\title{
The Relationships between Experience, Qualification and Subject Specialization and Content Knowledge Mastery of Economic and Management Sciences Teachers: A Case of Accounting Teaching
}

\author{
Habasisa Molise* \\ University of Limpopo, Polokwane, South Africa \\ Department of Education Studies, School of Education \\ https://orcid.org/0000-0002-3971-0718
}

\begin{abstract}
This paper investigates the relationship between teaching experience, qualification, and subject specialization on the content mastery of teachers of financial literacy to Grade 9 learners. The sample consisted of 89 Grade 9 teachers of financial literacy in the Thabo Mofutsanyana education district of South Africa. Data was collected using a questionnaire that elicited biographical data and required teachers of financial literacy to answer questions on a variety of accounting topics, to diagnose the effect of teaching experience, qualification, and subject specialization on the content knowledge mastery of the teachers. The data revealed three distinct themes, namely, solving the accounting equation, understanding accounting concepts, and the connection between topics and application of accounting principles. The items of the questionnaire were clustered into three constructs: accounting equation, accounting concepts, and accounting principles and subsidiary journals. The results show that having experience of teaching the subject, having relevant qualifications, and having a minor or major subject specialization in financial literacy enhances teachers' content knowledge and competence. This result suggests that teachers of financial literacy should have a minimum of three years of teaching experience before they teach senior classes, possess a relevant diploma or degree, and have had accounting as a subject until at least the second to the third year of their studies. In general, teachers should not be expected to teach subjects they did not specialize in, and their level of experience should be a determining factor in workload/subject allocation for teachers, especially for accounting (also known as financial literacy).
\end{abstract}

Keywords: accounting teaching; content knowledge; teaching experience; subject specialization; financial literacy

\footnotetext{
*Corresponding author: Habasisa Molise; Email: habasisa.molise@ul.ac.za
} 


\section{Introduction}

The paper explores the correlation between teaching experience, qualifications and subject specialization and the content mastery of teachers of financial literacy (FL) to Grade 9 learners. FL is a component of the subject economic and management sciences (EMS), commonly known as accounting in South Africa (Molise, 2020). Generally, teaching experience, qualifications and subject specialization are viewed as important variables, which contribute to the content mastery of teachers (Antony et al, 2019; Bamidele \& Adekola, 2017). When teachers are selected for employment, these variables may serve to determine the suitability of the teachers for teaching certain subjects (Bamidele \& Adekola, 2017). Much research has been done on the effect of teaching experience, qualifications and subject specialization on learners' academic achievement (Antony et al., 2019; Donkoh, 2017; Ladd \& Sorensen, 2017), yet we do not know whether teaching experience, qualification, and subject specialization are related to accounting content mastery by teachers (Emmanue \& Ambe, 2014; Musau \& Abere, 2015). Subject specialization level refers to the highest qualification obtained in the subject by a teacher (Myrberg et al., 2018). I argue that, in order to teach accounting, teachers should have studied accounting for at least two or three years of a diploma or degree qualification.

The South Africa, the minimum qualification for a teacher is a Bachelor's degree. However, most teachers at rural schools lack relevant qualifications to teach EMS, and they teach EMS because of their teaching experience in subjects such as economics and business studies (Ngwenya, 2020). Thus, EMS teachers struggle to teach FL, because schools do not consider teachers' qualifications and subject specializations when subject allocations are done (Modise \& Letlhoenyo, 2020). Studies have investigated the effect of teachers' experience of teaching, and their qualifications, to determine if these characteristics contribute to learner achievement (Nixon et al., 2016; Podolsky et al., 2019; Papay \& Kraft, 2015), and have found that the number of years spent teaching a particular subject, and qualifications relating to this subject, do not necessarily translate into academic achievement of learners (Nixon et al., 2016; Samad \& Nurusus, 2015). The studies found that several factors, in addition to experience and qualifications, could contribute significantly to academic achievement of learners, and the teaching strategies and methods teachers use (Podolsky et al., 2019; Hatlevik, 2017; Bamidele \& Adekola, 2017).

Studies found that teachers teach subjects in which they did not major, and that they lack the requisite experience and qualifications to teach those subjects (Modise \& Letlhoenyo, 2020). This situation compromizes learner achievement, also in the subject of FL. Ngwenya (2019) appreciates the importance of teachers' content knowledge mastery of accounting, which ensures that content is correctly transferred to learners. Accordingly, Samad and Nurusus (2015) argue that learners develop negative attitudes towards learning accounting, because it is presented in an abstract manner. Donkoh (2017) acknowledges that teachers are passionate about teaching, and suggests that teachers work tirelessly to make sure that EMS learners are taught, even though teachers may have poor content mastery of the subject. The findings reported above motivated this researcher to 
explore whether teachers' experience of teaching accounting, their teaching qualifications and whether they had specialized in accounting contribute to their content knowledge mastery.

This article focuses on the relationship that teaching experience, qualification, and subject specialization have with content mastery of teachers of FL to Grade 9 learners, as expressed by knowledge of the accounting equation, accounting concepts, and accounting principles.

\section{Literature review}

In this section, literature is presented to determine whether teaching experience, qualification, and subject specialization in accounting contribute to content knowledge mastery of teachers of EMS to Grade 9 learners. Shulman (1986) distinguishes between different kinds of knowledge that an effective teacher should possess. These include knowledge about the subject matter they are teaching (content knowledge), knowledge of specific strategies for teaching a particular subject matter (pedagogical content knowledge, PCK), and knowledge of the materials and media by which instruction and assessment are carried out (curricular knowledge). Content knowledge involves knowledge of the substance of the field; specialization concepts, principles, and procedures, and the relationships between these elements. Thus, "teachers must have an in-depth knowledge of the specific accounting topics that they teach as well as the accounting that their learners will learn in the future as teachers' subject knowledge impacts their behavior and thus indirectly affects learner achievement" (Molise, 2020, p. 460).

Several studies identified factors that can be associated with problems relating to content knowledge mastery of accounting teachers (Melo et al., 2020; Modise, 2016; Peter et al., 2017). These factors are classified as misconceptions, difficulties associated with defining accounting concepts, inability to manipulate accounting equations, and difficulty in applying accounting principles and procedures (Modise \& Letlhoenyo, 2020). These studies confirm that misconceptions are generally undesirable and must be identified and addressed (Melo et al., 2020; Peter et al., 2017). It is assumed that the reason for insisting on identifying and addressing misconceptions is to enhance the process of teaching and learning through effective content mastery by accounting teachers (Molise, 2020). I, thus, argue that, to improve learners' academic achievement, teachers should be able to present content in an appropriate way, and should ensure that the content is simplified by using context-based examples that learners can relate to when they learn about the accounting equation, concepts and principles.

Antony et al. (2019, p. 1) sought to assess secondary school teachers' characteristics in relation to qualifications and experience and found that teacher qualifications and teaching experience have a significant effect on biology teachers' TPACK. Findings of research into teacher qualifications (that is, the type of degree) are inconclusive. Some studies found a correlation between learner achievement and qualifications (Croninger et al., 2007; Brante, 2013), while others found negative effects (Musau \& Abere, 2015). Thus, "some argue that the 
requirement of a second degree raises the cost in terms of teacher education and the time it involves and may prevent quality candidates from choosing this profession" (Nixon et al., 2016, p. 1636). Teacher qualification refers to skills and knowledge an individual brings to improve teaching and learning conditions (Samad \& Nurusus, 2015), and it is suggested that a teacher has the ability to transfer knowledge to learners based on institutional recognition (Emmanue \& Ambe, 2014). In this study, teaching qualification relates to formal qualifications possessed by teachers, at any tertiary level.

Several studies confirm the importance of subject specialization (Nixon et al., 2015; Emmanue \& Ambe, 2014). These studies report that teachers have limited accounting content knowledge because they are generalists rather than specialists (Nixon et al., 2015), and they choose to spend their time and effort teaching other subjects. Secondary school teachers have to complete a specialization in their specialty subject before teaching it (Modise \& Letlhoenyo, 2020); the area of study is considered to be the teacher's area of expertise. In the senior phase, teachers are not required to have specialized in a subject, and it is doubtful whether teachers can show the same level of competence in all subjects (Modise, 2016). When they teach accounting, teachers need to focus on helping learners visualize accounting concepts and procedures (Qhosola, 2015) by using pictures and diagrams, rather than focusing only on doing calculations correctly (Molise, 2020). Several research studies report a positive relationship between teachers' preparation in the subject matter they later teach, and student achievement (Podolsky et al., 2016, p. 88), while others have less unequivocal results (Modise \& Letlhoenyo, 2020). DarlingHammond et al. (2017) argue that there is a correlation between teacher preparation and student achievement, and it can sometimes be negative. Thus, Myrberg et al. (2018, p 12) "find a positive relationship in mathematics, but none in science".

Also, Nixon et al. (2016, p 38) "report a positive relationship between student achievement and teachers' majoring in mathematics". Musau and Abere (2015, p. 84), however, found that having majored in mathematics does not affect learner performance, and could have a significant negative effect on teachers with more coursework in physical science. I argue that, when teachers have a limited conceptual understanding of accounting content knowledge, it influences their teaching effectiveness and ability to refine their mathematics instruction to match students' achievement. Therefore, teachers must teach the content in the simplest manner, to enable learners to understand it.

The next section will focus on the PCK model, which was adapted to interrogate the effect that teaching experience, qualification, and subject specialization have on the content knowledge mastery of accounting of teachers teaching FL to Grade 9 learners.

\section{Conceptual framework}

The PCK model is used in this paper to investigate the content mastery of teachers of FL, which the proponent of this model, Shulman, refers to as the "missing paradigm" in research on teaching and teacher knowledge (1986). PCK 
emphasizes representations and conceptions/misconceptions (McKlin et al., 2019), as used in this paper, "broadened ideas about how knowledge might matter to teaching" (Kuhn et al., 2016, p. 9), which shows that "it is not just knowledge of content, on the one hand, and knowledge of pedagogy" (Ngwenya, 2019, p. 22). There is a need for a relationship between content and pedagogy to exist (HungHsi, 2017).

Content knowledge comprises "knowledge of the subject and its organizational mechanisms" (Qhosola, 2015). Modise and Letlhoenyo (2020) believe that comprehending a teaching subject involves more than knowing its facts and concepts. According to Ngwenya (2020), educators must have full knowledge of institutional expectations of what is right and wrong to teach (Rahmi, 2018; Qhosola, 2015, p. 216). Moreover, the instructor is required to grasp why a specific topic is essential to a field, whilst another topic may be peripheral (Molise, 2020).

This framing assisted me to explore how teaching experience, qualifications, and subject specialization contribute to the content mastery of EMS teachers in relation to the accounting equation, accounting concepts, and principles, as entrenched throughout the EMS curriculum and South Africa's Curriculum and Assessment Policy Statement (CAPS). The framework assisted me to understand how teachers' orientations to content influenced the way they taught that content.

\section{Method}

This descriptive study employed a quantitative research approach to investigate the effect teaching experience, qualifications, and subject specialization have on the content knowledge mastery of FL teachers. A descriptive research study, according to Hlalele and Mosia (2020, p. 112), depicts "the particular characteristics of a scenario, a social context, a connection, or a depiction of a phenomena as it occurs naturally". The approach used in this study helped "to answer questions about the relationships among the measured variables such as teaching experience, qualifications and subject specialization with the purpose of explaining, predicting and controlling phenomena" (Bamidele \& Adekola, 2017, p. 3). It also helped me to determine the relationship between independent and dependent variables, with the aim of confirming a hypothesis about a phenomenon. The research was carried out in the Free State province's ThaboMofutsanyane education district. All Grade 9 teachers were requested to participate by completing a content-based FL questionnaire. I informed the participants of their rights, such as that they could disengage from the study without consequences, and that data generated through this research would be used for research purposes only (Touron et al., 2018). Therefore, the purpose of this study was to investigate the relationship between teaching experience, qualifications and subject specialization and the content mastery of FL teachers. The following sections will provide more details about the participants.

\subsection{Profile of participants}

The population comprised Grade 9 EMS teachers $(n=97)$ at rural intermediate schools in Thabo Mofutsanyane education district in the Free State province, South Africa; the study had 89 participants who were randomly selected. Data 
was generated by administering a questionnaire to EMS teachers. The questionnaire comprised two sections; the first section had 25 accounting questions, and the second elicited information on the biographical characteristics of teachers.

Table 1: Participants' demographic information

\begin{tabular}{llcc}
\hline Demographic variables & \multicolumn{1}{c}{ Category } & n & \% \\
\hline Experience & Less than 3 years & 64 & $72 \%$ \\
& 3 to 5 years & 15 & $17 \%$ \\
& 10 to 15 years & 7 & $9 \%$ \\
& 15 years and above & 3 & $3 \%$ \\
\hline Qualification(s) & Degree/ Diploma & 58 & $65 \%$ \\
& Degree plus PGCE* & 29 & $33 \%$ \\
& Honors degree & 2 & $2 \%$ \\
\hline Accounting level & No accounting & 25 & $28 \%$ \\
& First Year & 29 & $32 \%$ \\
& Second Year & 21 & $24 \%$ \\
& Third Year & 14 & $16 \%$ \\
\hline
\end{tabular}

*Postgraduate Certificate in Education

\subsection{Instrumentation}

A closed-ended questionnaire was administered to collect data on the relationships teaching experience, qualifications and subject specialization have on the content mastery of teachers who teach FL to Grade 9 learners. The questionnaire teased the problem areas of accounting topics, and was easy to complete, yet effective in collecting data.

After revision, the 23-item content-based questionnaire, with its four subscales/domains, covered the following subscales/domains: accounting equation; accounting concepts; accounting principles and FL (questions 9, 10, 12, 16,18 ). The questionnaire elicited biographical information (gender, age, teaching experience, qualifications, and subject specialization), to contextualize the teachers' answers and content challenges.

\subsection{Data analysis}

I used Statistica for data analysis. The mode of data analysis (Gaertner \& Brunner, 2018) underpinned the goal of the study, which was determining the relationships between teaching experience, qualification and subject specialization and the content knowledge mastery of teachers of FL to Grade 9 learners. Furthermore, the independent and dependent variables were also determined to either confirm or dispute the hypothesis relating to the phenomenon (Chang, et al., 2020; Gudmundsdottir \& Hatlevik, 2018; Mosia, 2014).

\subsection{Validity and reliability}

The tools used for data collection by this study were developed by a scholar at the University of the Free State, a senior accounting subject advisor who has 25 years of experience teaching and researching in the field of education. Officials of the Free State Education Department and the Educational, Training and Practices 
Development Sector Education and Training Authority evaluated and commented on the questionnaire. These government authorities were asked to verify whether the instrument did actually relate to the material necessary for FL education in Grade 9. The Cronbach's Alpha coefficient was used to assess the survey's reliability (Hlalele \& Mosia, 2020). A reliability value of 0.870 or above is deemed acceptable, and a reliability coefficient greater than 0.90 indicates that some questions are redundant, as they are evaluating the same question, but in a different form.

\section{Results}

This section presents data on the relationships between the variables of teaching experience, qualifications, and subject specialization level and the content mastery of teachers teaching FL to Grade 9 learners, concerning the constructs of accounting equation, accounting concepts, and accounting principles.

\subsection{Solving of the accounting equation}

Figure 1 depicts the proportion of teachers who gave incorrect answers in response to questions on solving accounting equations - a theme in Grade $9 \mathrm{FL}$ according to participants' teaching experience, qualifications, and subject specialization. The teaching experience of the teachers ranged from two years to more than 15 years, while their qualifications ranged from junior degrees with and without a teaching qualification, to honors degrees. The university level to which they had studied accounting ranged from zero to third-year level, with few of the teachers having studied accounting up to second-year level.

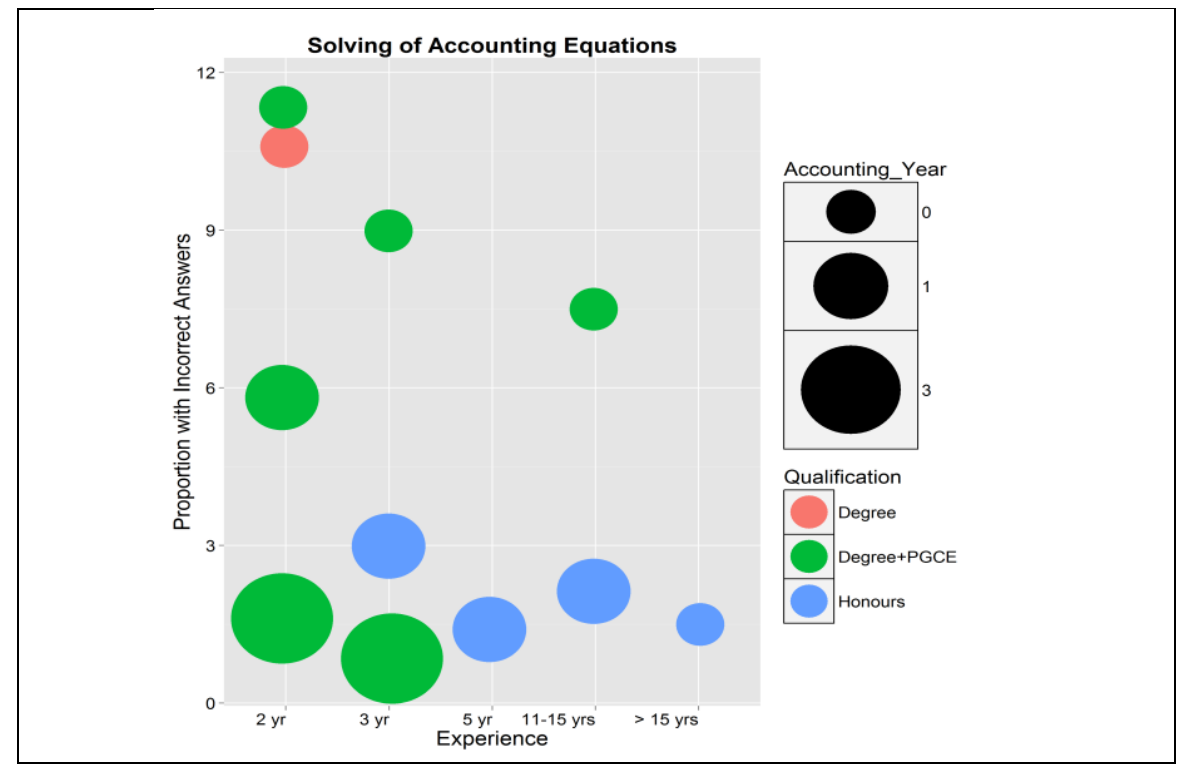

Figure 1. Incorrect answers on questions relating to accounting equation

Data in Figure 1 shows that, firstly, teachers with little teaching experience (no more than 2 years), and who did not have accounting as their subject specialization, had the highest number of incorrect answers - between 9 and 12 . This can be compared to teachers who had done accounting to first-year level, who had between 3 and 6 incorrect answers. In contrast, teachers with the same 
teaching experience (up to 2 years), a degree plus PGCE as qualification, but who had studied accounting up to their third year, had the lowest proportion of incorrect answers - at most 3 . Teachers with up to 2 years of teaching experience, with a degree but no accounting specialization, had a higher proportion of incorrect answers than teachers with the same experience and years of accounting specialization, who had degrees plus PGCE.

Secondly, teachers with teaching experience of maximum 3 years, with a degree plus PGCE, but without accounting as subject specialization, had 6 to 9 incorrect answers, while teachers with the same teaching experience and qualifications, who had specialized in accounting up to third year, gave the smallest proportion of incorrect answers - maximum 3. Teachers with the same teaching experience, with an honors degree and accounting at first-year level, had a lower proportion of incorrect answers than similarly experienced and qualified teachers who had not specialized in accounting at first-year level.

Thirdly, teachers with teaching experience of up to 5 years, with an honors degree and accounting at first-year level, gave the fewest incorrect answers - no more than 3. Teachers with the same qualification and first-year accounting, and between 11 and 15 years' experience, gave no more than 3 incorrect answers. Similarly, teachers with more than 15 years of experience, with an honors degree, but no specialization in accounting, gave few incorrect answers.

\subsection{Comprehension of accounting concepts and relationships between topics}

Figure 2 depicts the proportion of teachers who gave incorrect answers to questions in the questionnaire on comprehension of accounting concepts and relationships between topics and themes of Grade $9 \mathrm{FL}$, in relation to teaching experience, qualifications and subject specialization.

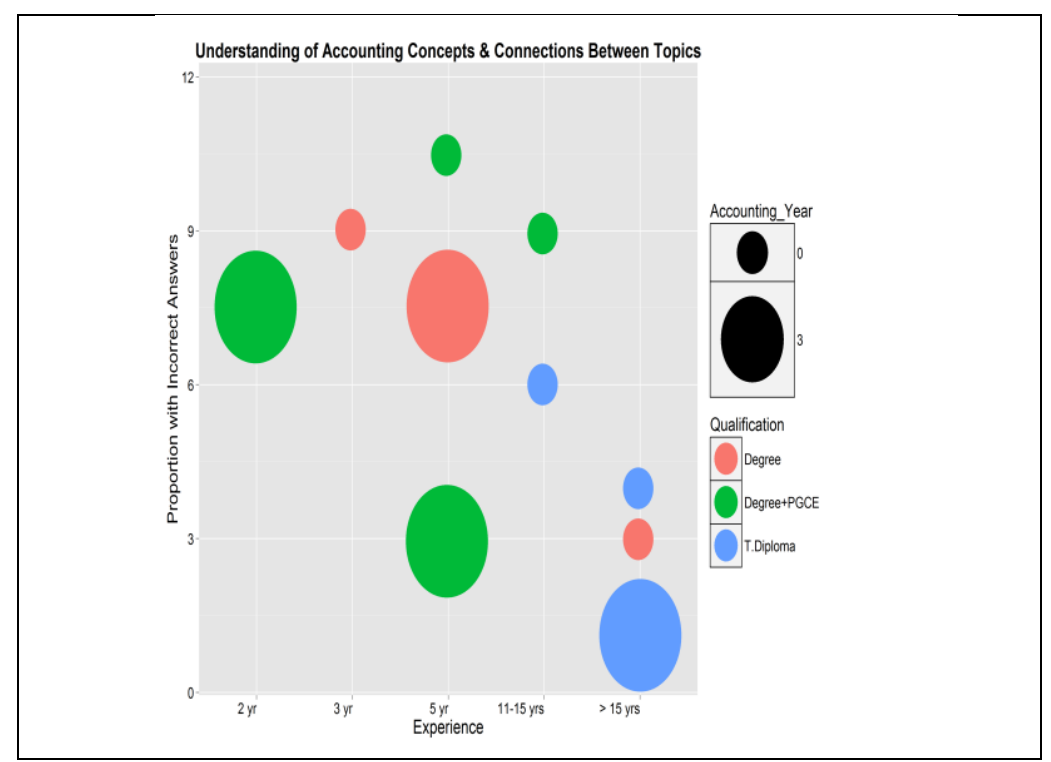

Figure 2. Incorrect answers on questions relating to understanding of accounting concepts Data in Figure 2 shows that, firstly, teachers who up to two years teaching experience and degrees plus PGCE, and who had specialized in accounting up to 
third-year level, had between 6 and 9 wrong answers. Secondly, teachers with up to three years teaching experience and degrees, but who had not had accounting as their subject specialization, had the highest proportion of incorrect answers, namely between 9 and 12 .

Thirdly, teachers with up to five years teaching experience and a degree plus PGCE, but who had not done accounting at first-year-level, had the highest proportion of incorrect answers (between 9 and 12). In turn, teachers with the same teaching experience and qualification, but with accounting at third-year level, had a lower proportion of incorrect answers - maximum 3. In contrast, teachers with the same teaching experience but with accounting at third-year level, and a degree, had a higher proportion of incorrect answers than those with the same experience and specialization, but with a degree plus PGCE. Fourthly, teachers with teaching experience of between 11 and 15 years, holding a degree plus PGCE, who had not specialized in accounting, had a higher proportion of incorrect responses than teachers with the same teaching experience and accounting subject specialization level, yet with a teachers' diploma.

Lastly, teachers with teaching experience of more than 15 years, holding a teacher diploma and having done third-year-level accounting subject specialization, had the lowest proportion of incorrect answers - no more than 3 - compared to teachers with the same teaching experience and qualification, but without accounting as their subject specialization.

\subsection{Application of accounting principles}

Figure 3 depicts the proportion of teachers who chose incorrect answers in the questionnaire on the theme application of accounting principles of Grade $9 \mathrm{FL}$ teaching, according to teaching knowledge, qualifications, and subject specialization.

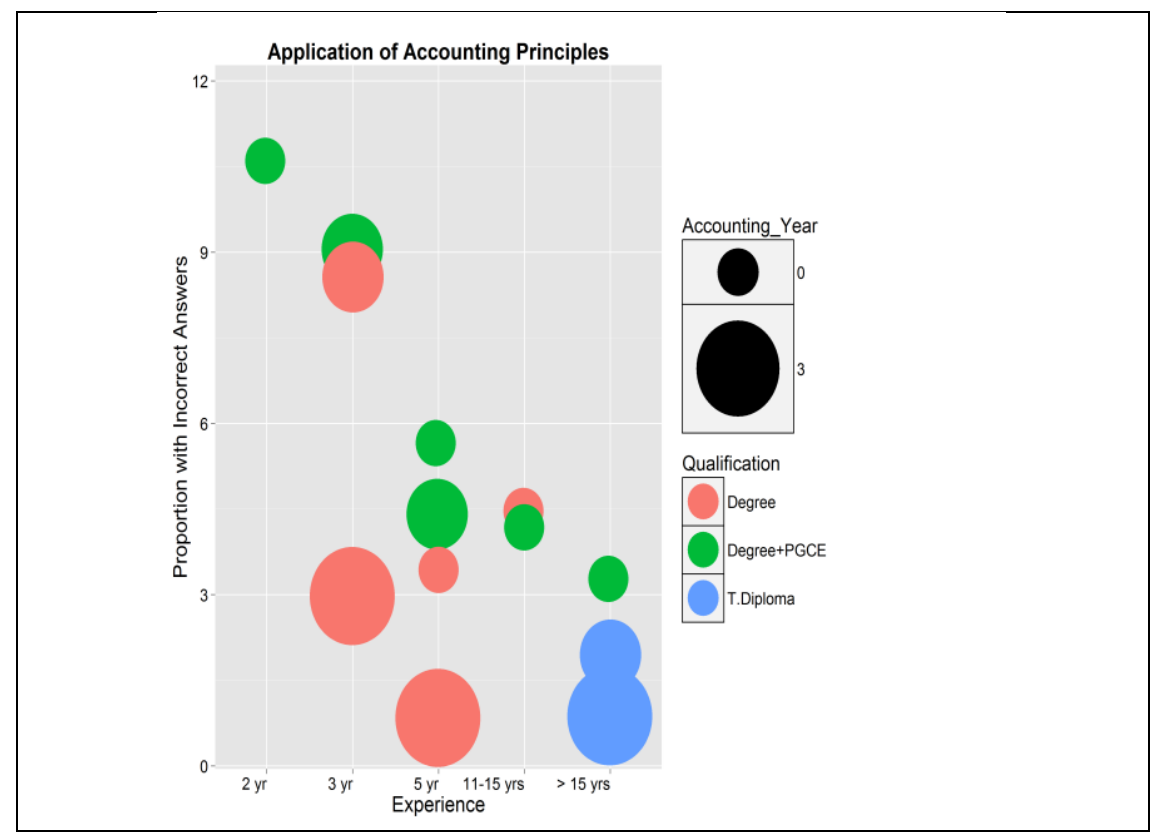

Figure 3. Incorrect answers on questions relating to accounting principles 
Data in Figure 3 shows that, firstly, teachers who have at most two years of teaching experience, and who hold a degree plus PGCE, and who had not specialized in accounting, had the highest proportion of incorrect answers.

Secondly, teachers with teaching experience of up to 3 years, who have a degree and had third-year level accounting as their subject specialization, had a lower proportion of incorrect answers, at most 3 , compared to teachers with the same teaching experience and qualification, who had a high number of incorrect answers - between 6 and 9. Similarly, teachers with the same teaching experience, no more than 3 years, with a degree plus PGCE, but who did not specialize in accounting at all, had the highest number of incorrect answers, that is, between 9 and 12.

Thirdly, teachers who have up to five years teaching experience, who hold a degree, and who specialized in accounting up to third-year level, had the lowest proportion of incorrect answers, that is, at most 3. Other teachers, with the same teaching experience and qualification, yet do not have accounting subject specialization, had a lower number of incorrect answers, that is, between 3 and 6 . Similarly, teachers with the same teaching experience, and holding a degree plus PGCE, with no accounting specialization, had a low proportion of incorrect answers, that is, between 3 and 6 .

Fourthly, teachers who had teaching experience of between 11 to 15 years, who have a degree plus PGCE, but who had not specialized in accounting, had a lower proportion of incorrect answers than teachers with only a degree, but the same experience and first-year accounting.

Lastly, teachers with teaching experience of more than 15 years, who hold a diploma and who had specialized in accounting at third-year level, had the lowest proportion of incorrect answers - no more than 3. Similarly, teachers with the same teaching experience and qualification, yet do not have accounting subject specialization, had a lower number of incorrect answers, that is, no more than 3. In contrast, teachers with the same years of teaching experience and who had no accounting subject specialization, and a degree plus PGCE, had a higher proportion of incorrect answers than teachers with a diploma.

\section{Discussion of results}

This section discusses results concerning solving the accounting equation, comprehension of accounting concepts, and relations between topics and application of accounting principles. The reviewed literature confirms that teachers must have a thorough comprehension of the specific accounting topics they teach (Molise, 2020). However, most of the teachers who teach EMS are confronted with serious accounting content misconceptions, which threaten effective teaching of FL topics to Grade 9 learners (Melo et al., 2020; Modise, 2016; Peter et al., 2017). Modise and Letlhoenyo (2020) confirm that misconceptions are generally undesirable and must, therefore, be identified and addressed. The majority of the teachers in the study struggled to analyze transactions in the 
accounting equation, lacked comprehension of accounting concepts and how they link with other concepts, and they were unable to apply accounting principles.

Firstly, the results show that teaching experience, qualifications, and subject specialization play pivotal roles in the content mastery of EMS teachers in relation to solving the accounting equation. It was evident from the analysis that teachers with a degree plus PGCE, and who had specialized in accounting at third-year level, had a lower number of incorrect answers - at most 3 - and the number decreased further as they gained more teaching experience. Similarly, the number of wrong answers of teachers with a degree plus honors, with accounting at firstyear level, decreased from 3 to 0 as they gained more experience, first from 3 to 5 years and then from 11 to 15 years. Even teachers with no accounting specialization, with a degree plus honors, are likely to experience a decrease in the proportion of incorrect answers when they reach 15 years of teaching experience. Therefore, more teaching experience is acquired by accounting teachers who have a relevant degree and who had specialized in accounting for three years - they had a lower proportion of incorrect answers.

Secondly, it is evident from the analysis that teachers with a degree plus PGCE, with a third-year level accounting subject specialization, decreased the proportion of incorrect answers (from 3 to 0 ), as they gained more teaching experience (from 3 to 5 years). Similarly, teachers with a diploma, with a third-year accounting specialization, showed a considerable decrease in the proportion of incorrect answers (from 3 to 0 ), as they reached 15 years of experience.

Thirdly, it is evident from the analysis that there was a considerable decrease in the proportion of incorrect answers, from 3 to 0 , for teachers holding a degree with a third-year accounting subject specialization as they gained more teaching experience (from 3 to 5 years). Similarly, teachers with a diploma, with no accounting specialization, show a considerable decrease in the proportion of incorrect answers, from 3 to 0 , as they reach 15 years of experience. I recommend appointing EMS teachers who have a degree or diploma that included the study of accounting, economics, and business studies up to second to third-year level for them to ensure content mastery, especially the accounting part (referred to as FL in the CAPS document) of EMS.

The author argues that content misconceptions by teachers (as illustrated by incorrect answers on the questionnaire) are not unique to accounting, and that intervention strategies through content-specific workshops and cluster teaching collaboration must be implemented to improve teachers' content skills in all subjects.

\section{Limitations}

The research was done in a single education district of the Free State province, South Africa, and data was generated using a single tool, a closed-ended questionnaire. 


\section{Conclusion}

This paper aimed to explore the relationships between teaching experience, qualification, and subject specialization on the content mastery of teachers of FL (the accounting part of EMS) to Grade 9 learners. The results show that the experience of the teacher in teaching the subject, relevant qualifications, and having specialized in accounting to the second or third-year level enhances teachers' content knowledge and competence. It is worth noting that teachers who had relevant teaching qualifications with accounting as their subject of specialization at either second or third-year level contributed less to the proportion of incorrect answers regarding the accounting equation, accounting concepts, and principles. However, most of the teachers who contributed to a higher proportion of incorrect answers did not have a relevant accounting teaching qualification and had not specialized in the subject during their training. Similarly, teachers who had 3-15 years of teaching experience had fewer incorrect answers because they have been teaching the subject for more than 3 years.

I, therefore, recommend that teachers strive to gain at least three years of teaching experience before they teach senior classes, that they have a relevant diploma or degree that involved studying accounting to at least the second or third year. Teachers should refrain from teaching subjects in which they did not specialize; the teacher's level of experience should be a determining factor in doing workload/subject allocation for EMS teachers, especially for accounting/FL. Teachers must receive continuous professional development support, to help address inherent content knowledge misconceptions they may have.

\section{References}

Antony, M. K., Paidy, H., Subali, B., Pradana, S. P., Hapsari, N., \& Astuti, F. E. C. (2019). Teacher's TPACK profile: The effect of teacher qualification and teaching experience. Journal of Physics: Conference Series, 6, 1-6. https://doi.org/10.1088/1742-6596/1397/1/012054

Bamidele, A. D., \& Adekola, F. F. (2017). Effects of teacher's qualifications and teaching experience on students' academic achievement in basic science in junior secondary school. International Journal of Education and Evaluation, 3(2), 1-9.

Brante, T. (2013). The professional landscape: the historical development of professions in Sweden. Professions and Professionalism, 3(2), 1-18. https://doi.org/10.7577/pp.558

Chang, S. H., Ward, P. \& Goodway, J. D. (2020) The effect of a content knowledge teacher professional workshop on enacted pedagogical content knowledge and student learning in a throwing unit. Physical Education and Sport Pedagogy, 25(5), 493-508. https://doi.org/10.1080/17408989.2020.1743252

Croninger, R. G., King Rice, J. K., Rathbun, A., \& Nishio, M. (2007). Teacher qualifications and early learning: effects of certification, degree, and experience on first-grade student achievement. Economics of Education Review, 26(3), 312-324.

Darling-Hammond, L., Burns, D., Campbell, C., Goodwin, A. L., Hammerness, K., Low, E. L. McIntyre, A., Sato, M., \& Zechner, K. (2017). Empowered educators: How highperforming systems shape teaching quality around the world. John Wiley \& Sons.

Donkoh, S. (2017). Investigating the effect of teaching experience on teacher knowledge. International Journal of Scientific and Research Publications, 7(6), 319-327. 
Emmanue, I. A. \& Ambe, B. A. (2014). Influence of teachers, professional qualification and area of specialisation on the implementation of environmental education curriculum in Cross River State - Nigeria. International Conference on Chemical, Environment $\mathcal{E}$ Biological Sciences (CEBS) (155-160). http://dx.doi.org/10.15242/IICBE.C914120

Gaertner, H., \& Brunner, M. (2018). Once good teaching, always good teaching? The differential stability of student perceptions of teaching quality. Educational Assessment, Evaluation and Accountability, 30, 159-182. https://doi.org/10.1007/s11092-018-9277-5

Gudmundsdottir, G. B. Hatlevik, O. E. (2018). Newly qualified teachers' professional digital competence: Implications for teacher education. European Journal of Teacher Education, 41, 214-231. https://doi.org/10.1080/02619768.2017.1416085

Hatlevik, I. K. (2017). The impact of prospective teachers' perceived competence on subsequent perceptions as schoolteachers. Teachers and Teaching: Theory and Practice, 23(7), 810-828. https:/doi.org/10.1080/13540602.2017.1322056.

Hlalele, D., \& Mosia, M. (2020). Teachers' sense of community in rural learning ecologies. Alternation, 27(2), 101-124. https:// doi.org/10.29086/2519-5476/2020/v27n2a6

Hung-Hsi, W. (2017). The content knowledge mathematics teachers need. In Y. Li, W. J. Lewis, \& J. Madden (Eds.), Mathematics Matters in Education. Essays in honour of Roger E. Howe (43-91). Springer.

Kuhn, C., Alonzo, A.C., \& Zlatkin-Troitschanskaia, O. (2016). Evaluating the pedagogical content knowledge of pre-and in-service teachers of business and economics to ensure the quality of classroom practice in vocational education and training. Empirical Research in Vocational Education and Training, 8(5), 1-18. https://doi.org/10.1186/s40461-016-0031-2

Ladd, H. F., \& Sorensen, L. C. (2017). Returns to teacher experience: Student achievement and motivation in middle school. Education Finance and Policy, 12(2), 241-279. http://direct.mit.edu/edfp/article-pdf/12/2/241/1691525/edfp

McKlin, T., Lee, T., Wanzer, D., Magerko, B., Edwards, D., Grossman, S., Bryans, E., \& Freeman, J. (2019). Accounting for pedagogical content knowledge in a theory of change analysis. In ICER '19: International Computing Education Research Conference (12-14). Association for Computing Machinery. https://doi.org/10.1145/3291279.3339412

Melo, L. Cañada-Cañada, F., González-Gómez, D., \& Jeong, J. S. (2020). Exploring pedagogical content knowledge (PCK) of physics teachers in a Colombian $\begin{array}{llll}\text { secondary school. Education } & \text { Science, }\end{array}$ https://doi.org/10.3390/educsci10120362

Molise, H. (2020). Exploring the content knowledge of accounting teachers in rural contexts: A call for a decoloniality approach. International Journal of Learning, Teaching and Educational Research, 19(8), 447-458. https://doi.org/10.26803/ijlter.19.8.24

Modise, M. A. (2016). Pedagogical content knowledge challenges of accounting teachers. International Journal of Educational Science, 13(3), 291-297.

Modise, M. A. \& Letlhoenyo, S. (2020). Pedagogical content knowledge of accounting teachers in South Africa: Readiness of Grade 9 for accounting in Grade 10. Proceedings of ADVED 2020- 6th International Conference on Advances in Education, (79-80).

Mosia, M. S. (2014). Gender differentials and the mathematics performance of Grade 10 to 12 learners at the Dilanedi Schools. Mediterranean Journal of Social Sciences, 5(23), 1426-1431. https://doi.org/10.5901/mjss.2014.v5n23p1426 
Musau, L. M., \& Abere, M. J. (2015). Teacher qualification and students' academic performance in science mathematics and technology subjects in Kenya. International Journal of Educational Administration and Policy Studies, 7(3), 83-89.

Myrberg, E., Johansson, S., \& Rosén, M. (2018). The relation between teacher specialisation and student reading achievement. Scandinavian Journal of Educational Research, 63(5), 1-15. https://doi.org/10.1080/00313831.2018.1434826

Ngwenya, J. (2019). Accounting teachers' experiences of communal feedback in rural South Africa. South African Journal of Education, 32(2), S1-S10. https://doi.org/10.15700/saje.v39ns2a1502

Ngwenya, J. C. (2020). Assets teachers identify for the teaching of Accounting Education in a rural school in KwaZulu-Natal. Perspectives in Education, 38(1), 72-87. http://dx.doi.org/10.18820/2519593X/pie.v38i1.6

Nixon, R. S., Campbell, B. K., \& Luft, J. A. (2016). Effects of subject-area degree and classroom experience on new chemistry teachers' subject matter knowledge. International Journal of Science Education, 2016(38), 1636-1654. https:// doi.org/10.1080/09500693.2016.1204482

Papay, J. P., \& Kraft, M. A. (2015). Productivity returns to experience in the teacher labor market: Methodological challenges and new evidence on long-term career improvement. Journal of Public Economics, 130, 105-119. https://doi.org/10.1016/j.jpubeco.2015.02.008

Peter, I., Ward, P., \& Li, W. (2017). Effects of improved content knowledge on pedagogical content knowledge and student performance in physical education. Physical Education and Sport Pedagogy, 22(1), 71-88.

Podolsky, A., Kini, T., Bishop, J. and Darling-Hammond, L. (2016), Solving the teacher shortage: How to attract and retain excellent educators. Learning Policy Institute. https://learningpolicyinstitute.org/sites/default/files/productfiles/Solving_Teacher_Shortage_Attract_Retain_Educators_REPORT.pdf

Podolsky, A., Kini, T., \& Darling-Hammond, L. (2019). Does teaching experience increase teacher effectiveness? A review of US research. Journal of Professional Capital and Community, 4, 286-308. https://doi.org/ 10.1108/JPCC-12-2018-0032

Qhosola, M. R. (2015). Accounting teacher preparation: A critical accounting perspective. Journal of Higher Education Association/Research in Education Southern Africa, 13(1\&2), 213-222.

Rahmi, E. (2018). The analysis of pedagogical content knowledge of teacher candidates. Advances in Economics, Business and Management Research, 57, 604-609.

Samad, A., \& Nurusus, E. (2015). The influence of teaching experience, school location and academic background on teachers' beliefs in teaching grammar. Asian Social Science, 11(15), 257-266.

Shulman, L. S. (1986). Those who understand: Knowledge growth in teaching. Educational Researcher, 15(2), 4-14.

Touron, J., Martin, D. R., Navarro Asencio, E., Pradas, S., \& Inigo, V. (2018). Construct validation of a questionnaire to measure teachers' digital competence (TDC). Spanish Journal of Pedagogy, 76, 25-54. https://doi.org/10.22550/REP76-1-2018-02 